This is the final peer-reviewed accepted manuscript of

Capolupo, Marco; Franzellitti, Silvia; Valbonesi, Paola; Lanzas, Claudia Sanz; Fabbri, Elena: Uptake and transcriptional effects of polystyrene microplastics in larval stages of the Mediterranean mussel Mytilus galloprovincialis. ENVIRONMENTAL POLLUTION, 241. ISSN 0269-7491

DOI: 10.1016/j.envpol.2018.06.035

The final published version is available online at:

http://dx.doi.org/10.1016/j.envpol.2018.06.035

Rights / License:

The terms and conditions for the reuse of this version of the manuscript are specified in the publishing policy. For all terms of use and more information see the publisher's website.

This item was downloaded from IRIS Università di Bologna (https://cris.unibo.it/)

When citing, please refer to the published version. 


\title{
Uptake and transcriptional effects of polystyrene microplastics in larval stages of the Mediterranean mussel Mytilus galloprovincialis
}

\author{
Marco Capolupo a, b, *, 1 , Silvia Franzellitti ${ }^{\text {a, b, } 1 \text {, Paola Valbonesi }}{ }^{\text {a }}$, Claudia Sanz Lanzas ${ }^{\text {, }}$ \\ Elena Fabbri a,b \\ a University of Bologna, Department of Biological, Geological, and Environmental Sciences, P.zza di P.ta S. Donato 1, 40100 Bologna, Italy \\ b University of Bologna, Inter-Departmental Research Centre for Environmental Science (CIRSA), Via S. Alberto 163, 48123 Ravenna, Italy \\ ${ }^{\mathrm{c}}$ Valencia Catholic University Saint Vincent Martyr, Faculty of Veterinary and Experimental Sciences, C/ Guillem de Castro 94, 46001, Valencia, Spain
}

\section{A R T I C L E I N F O}

Keywords:

Microplastics

Marine mussels

Uptake

Embryotoxicity

Gene transcription

\section{A B S T R A C T}

The widespread occurrence of microplastics (MP) in the marine environment is cause of increasing concerns about the safety of the exposed ecosystems. Although the effects associated to the MP uptake have been studied in most marine taxa, the knowledge about their sub lethal impacts on early life stages of marine species is still limited. Here, we investigated the uptake/retention of $3 \mu \mathrm{m}$ polystyrene MP by early stages of the Mediterranean mussel Mytilus galloprovincialis, and the related effects on gut clearance, feeding efficiency, morphological and transcriptional parameters involved in embryo larval development. Uptake measurements were performed on larvae at 48 h, 3, 6 and 9 days post fertilization (pf) after exposure to a range of 5010,000 particles $\mathrm{mL}^{1}$. At all tested pf periods, treatments resulted in a significant and linear increase of MP uptake with increasing concentrations, though levels measured at 48 $\mathrm{h}$ pf were significantly lower compared to $39 \mathrm{~d}$ pf. Ingested MP were retained up to $192 \mathrm{~h}$ in larvae's gut, suggesting a physical impact on digestive functions. No change was noted between the consumption of microalgae Nannochloropsis oculata by larvae when administered alone or in the presence of an identical concentration (2000 items $\mathrm{mL}^{1}$ ) of MP. The exposure to $5010,000 \mathrm{MP} \mathrm{mL}^{1}$ did not alter the morphological development of mussel embryos; however, transcriptional alterations were observed at 50 and $500 \mathrm{MP} \mathrm{mL}{ }^{1}$, including the up regulation of genes involved in shell biogenesis (extrapallial protein; carbonic anhydrase; chitin synthase) and immunomodulation (myticin C; mytilin B), and the inhibition of those coding for lysosomal enzymes (hexosaminidase; $\beta$ glucorinidase; catepsin $\mathrm{L}$ ). In conclusion, though not highlighting morphological or feeding abnormalities, data from this study revealed the onset of physical and transcriptional impairments induced by MP in mussel larvae, indicating sub lethal impacts which could increase their vulnerability toward further environ mental stressors.

\section{Introduction}

Over the past decades, most of the glass, wooden or metal made items used in the daily life have been progressively replaced by lighter, cheaper and more durable plastic made counterparts, so that the current historical period has been cited as "the Age of Plastic" (Avio et al., 2017). However, besides the multiple benefits

\footnotetext{
This paper has been recommended for acceptance by Baoshan Xing.

* Corresponding author. Inter-Departmental Research Centre for Environmental

Science (CIRSA), University of Bologna, Via S. Alberto 163, 48123 Ravenna, Italy.

E-mail address: marco.capolupo2@unibo.it (M. Capolupo).

1 Equally contributed to the work.
}

brought by plastic to the human society, increasing concerns are risen as to the impacts associated to its ubiquity within natural systems (UNEP, 2016). Currently, plastics account for the $80-90 \%$ of the whole marine litter (Derraik, 2002), and over 5 trillion microscopic plastic fragments are estimated to float into the World Oceans (Eriksen et al., 2014). These particles, referred to as microplastics (MP) based on their $<5 \mathrm{~mm}$ size (GESAMP, 2016), can directly enter the marine environment as microscopic items (primary MP), or deriving from the progressive fragmentation of larger plastics due to weathering processes (secondary MP) (Andrady, 2011). Depending on their size, shape and chemical composition, MP assume different positions and behaviours along the water column, being easily mistaken for natural food/preys by a vast 
range of marine species (Galloway et al., 2017).

In recent years, increasing attention has been focused on the potential adverse effects induced by MP on the marine species ontogeny (UNEP, 2016). Given their incomplete neuromorphological development, early life stages of aquatic species display a higher vulnerability to external challenges compared to adults (Mohammed, 2013). This assumption is particularly critical for marine sessile invertebrates, whose resilience or spatial dispersion depend on recruitment pathways governed by plank tonic larvae. Bivalve and echinoderm larvae are widely employed for ecotoxicological investigations, given their high responsiveness to physical and chemical stressors, ease of rearing and adaptability to in vitro experimental designs (Fabbri et al., 2014; Passarelli et al., 2018). A study from Kaposi et al. (2014) showed a concentration dependent uptake of polyethylene MP by larvae of the sea urchin Tripneustes gratilla, and reduced body width only at the highest dosage of $300 \mathrm{MP} \mathrm{mL}^{-1}$.

The exposure to increasing concentrations of polystyrene MP also affected filtration rates in embryos of different asteroid and sea urchin species (Lizarraga et al., 2017). In larvae of the Pacific oyster (Crassostrea gigas), the capability to ingest polystyrene MP of different sizes was reported to be a function of the development stage (Cole and Galloway, 2015). Polystyrene MP $(2-6 \mu \mathrm{m})$ were found to alter the expression of genes involved in gamete differentiation and maturation over a 8 week exposure in adult $C$. gigas (Sussarellu et al., 2016).

Whether the ingestion of plankton sized MP induce morphological and/or transcriptional effects in early stages of marine bivalves is still unclear. Therefore, in the present study, experiments were performed to evaluate the uptake of polystyrene MP by early life stages of the Mediterranean mussel (Mytilus galloprovincialis) and the related effects on multiple endpoints. M. galloprovincialis is widely distributed in urbanized coastal environments thus likely being exposed to MP sources for its entire life cycle; it is also a species of high ecological and commercial importance, and worldwide utilized as sentinel organism of pollution in coastal marine environments (Viarengo et al., 2007). Establishing the impacts of MP on mussel early life stages is thus important to gain significant insights on the adverse consequences of plastic pollution.

Ingestion and accumulation of MP was microscopically assessed in mussel larvae at different developmental times and increasing MP concentrations. The retention of ingested particles by larvae was evaluated by measuring their egestion over time. Co exposure to MP and microalgae (Nannochloropsis oculata) was performed to evaluate potential influences of MP occurrence on food consumption. Finally, in agreement with recent studies (Balbi et al., 2016, 2017), morphological alterations and expression changes of transcripts involved in shell biogenesis, neuroendocrine signaling, detoxification/antioxidant processes, and immune responses were evaluated in mussel embryos grown in the presence of MP to investigate the potential impacts on larval development of mussels.

\section{Materials and methods}

\subsection{Polystyrene microplastics (MP)}

Fluorescently labeled polystyrene microspheres (Fluoresbrite Plain YG, $441 / 486 \mathrm{~nm}$ excitation/emission; $3 \pm 0.15 \mu \mathrm{m}$ diameter) were purchased from Polyscience Inc. (Washington, PA, USA). Such particles were chosen as a proxy of MP exposure since their density $\left(1.05 \mathrm{~g} / \mathrm{cm}^{3}\right)$ is almost identical to that of seawater $\left(1.025-1.035 \mathrm{~g} / \mathrm{cm}^{3}\right.$ according to the UNESCO, 1981), so that they should not sink within 24-48 $\mathrm{h}$ from suspension in water. The MP diameter was chosen based on the size of phytoplanktonic species commonly preyed by bivalve larvae (Southgate et al., 2017). Surfactants were not present or added to the original MP suspension $\left(1.69 \times 10^{9} \mathrm{MP} \mathrm{mL}{ }^{-1}\right)$, whose medium was ultrapure $\mathrm{H}_{2} \mathrm{O}$ (Polyscience, inc.). A stock solution of $10^{7} \mathrm{MP} \mathrm{mL}^{-1}$ was prepared in milli $\mathrm{Q} \mathrm{H}_{2} \mathrm{O}$, aliquoted and stored at $4{ }^{\circ} \mathrm{C}$ according to the manufacturer's specification. At each MP administration, 1 aliquot of the stock solution was serially diluted in filtered $(0.22 \mu \mathrm{m})$ seawater (FSW) to achieve the suitable volume to be added to each experimental treatment. Before spiking, the lack of aggreg tion was verified by epifluorescence microscopy (Zeiss Observer, Axiovert S100, 20-40 $\times$ magnification) at $\lambda_{\text {excitation }} 365 \mathrm{~nm}$ and $\lambda_{\text {emission }} 397$ $\mathrm{nm}$.

\subsection{Animal holding and oocyte fertilization}

Sexually mature specimens of Mediterranean mussel ( $M$. galloprovincialis) were collected from a government certified mussel farm (COPRALMO, Cesenatico, Italy), immediately transported to the laboratory, and acclimated for 3 days in static tanks containing filtered seawater (FSW) at $16{ }^{\circ} \mathrm{C}$ and at a density of 5 mussels $\mathrm{L}^{-1}$. Gamete collection, oocyte fertilization and larvae handling were performed following the procedure described by Fabbri et al. (2014). Briefly, when mussels begun to spontaneously spawn, each individual was placed in a $250 \mathrm{~mL}$ beaker containing $200 \mathrm{~mL}$ of aerated FSW until complete gamete emission. After spawning, mussels were removed from beakers and sperms and eggs sieved through $50 \mu \mathrm{m}$ and $100 \mu \mathrm{m}$ nylon meshes, respectively, to remove impurities. Egg quality (shape, size) and sperm motility were checked using an inverted light microscope $(\mathrm{OPTECH}$, IB series; Munchen, Germany; $40 \times$ magnification). Pools of gametes from at least three specimens per sex were employed for experimental purpose. Eggs were fertilized with a 1:10 egg to sperm ratio in the suited experimental systems (see detailed description below). In any case, embryos were grown at $16{ }^{\circ} \mathrm{C} \pm 1{ }^{\circ} \mathrm{C}$ with a 16 h: $8 \mathrm{~h}$ (light: dark) photoperiod and continuous aeration.

\subsection{MP uptake and retention by mussel larvae and effects on food consumption}

\subsubsection{Experimental treatment}

Oocyte fertilization was performed as previously described in 2 L glass beakers containing $1.5 \mathrm{~L} \mathrm{FSW} \mathrm{(35} \mathrm{eggs} \mathrm{mL}^{-1}$ ) (S1 stock culture). Starting from $48 \mathrm{~h}$ post fertilization (pf), larvae were fed daily with a suspension of microalgae ( $N$. oculata; 1200 cell $\mathrm{mL}^{-1}$ ). Every 3 days, larvae were collected by sieving the S1 culture on a nylon mesh (20 $\mu \mathrm{m}$ pore filter) and employed for experimental treatments as described below. At each time interval, unemployed larvae were re suspended in FSW and the S1 rearing conditions restored.

\subsubsection{Uptake of polystyrene $M P$}

Larvae were collected at $48 \mathrm{~h}, 3,6$ and 9 days pf, from the S1 stock and aliquoted in 12 well plates at a density of 50 larvae $\mathrm{mL}^{-1}$ in a total volume of $3 \mathrm{~mL}$ FSW. MP were added to each well to obtain final nominal concentrations from $50 \mathrm{MP} \mathrm{mL}^{-1}$, which is the lowest concentration allowing all exposed larvae (50 organisms $\mathrm{mL}^{-1}$ ) to feed on suspended particles (MP to larvae ratio $1: 1$ ), to $10,000 \mathrm{MP} \mathrm{mL} \mathrm{mL}^{-1}$, which is comparable to the microalgae concen tration at which the maximum ingestion rate was measured in mussel larvae (Sprung, 1984). Treatments were performed in quadruplicate. After $24 \mathrm{~h}$ of exposure, samples were fixed with buffered formalin (4\%). MP uptake by larvae was assessed using an inverted epifluorescence microscope (Zeiss Observer, Axiovert S100; $20-100 \times$ magnification) equipped with a 365/397 $\mathrm{nm}(\lambda$ excitation $/ \lambda$ emission) filter. Data were expressed as the 
mean \pm SEM of the percentage of larvae showing MP ingestion or the number of ingested MP larva ${ }^{-1}\left(\begin{array}{ll}N & 4\end{array}\right)$.

\subsubsection{Retention of ingested $M P$}

Larvae were collected at $6 \mathrm{~d}$ pf from the S1 stock and added to $100 \mathrm{~mL}$ glass beakers containing $50 \mathrm{~mL}$ of FSW (50 larvae $\mathrm{mL}^{-1}$ ). MP stock solution was diluted into each beaker to obtain a final nominal concentration of $1000 \mathrm{MP} \mathrm{mL}^{-1}$. After $24 \mathrm{~h}$ of exposure, the beakers content was pooled in a $100 \mathrm{~mL}$ PVC container having a sieved bottom ( $20 \mu \mathrm{m}$ nylon filter mesh) to isolate larvae from eventually non ingested MP. Rapidly, the container was half sub merged in $6 \mathrm{~L}$ tanks containing $5 \mathrm{~L}$ FSW, and thereby blocked by mechanical support to allow egested MP to pass through the sieved bottom and avoid re ingestion. At $2 \mathrm{~h}$ intervals for the first $12 \mathrm{~h}$, and every $12 \mathrm{~h}$ thereafter, aliquots of about 150 larvae were collected from each treatment condition and fixed with $4 \%$ buffered formalin. At each time interval, the number of larvae showing ingested MP was examined by an inverted fluorescence microscope (Zeiss Observer, Axiovert S100; 20-100 $\times$ magnification) and the FSW volume contained in each $6 \mathrm{~L}$ tank renewed. The assessment was stopped when two consecutive sampling showed no D veligers with ingested MP. Data were expressed as mean \pm SEM (N 4) of the percentage of larvae showing MP over time.

\subsubsection{Effects of MP on food consumption}

The effects of MP on food consumption were evaluated by measuring the uptake of microalgae $N$. oculata by larvae either in the presence or absence of the selected MP. Six d pf larvae were collected from the S1 stock and placed into $100 \mathrm{~mL}$ beakers containing $50 \mathrm{~mL} \mathrm{FSW}$ at a density of 50 larvae $\mathrm{mL}^{-1}$. All treatments were performed using total item concentration (i.e. MP, algae, or MP + algae) far below levels at which the maximum ingestion rate is expectable in mussel larvae (around 10,000 items $\mathrm{mL}^{-1}$ according to Sprung, 1984), to avoid satiation or gut saturation. MP and/or microalgae were added to each beaker to obtain a mixture containing each item (MP and algae) at a concentration of 2000 particle $\mathrm{mL}^{-1}$. Single exposures to algae (2000 cell $\mathrm{mL}^{-1}$ ) or MP (2000 particles $\mathrm{mL}^{-1}$ ) were also performed. For each treatment, a control condition containing no larvae was maintained in parallel. All treatments were performed in quadruplicate (N 4). After 24 h, samples were filtered on a $20 \mu \mathrm{m}$ nylon filter mesh to eliminate larvae and the solution was centrifuged at $1100 \times g$ for $10 \mathrm{~min}$. The obtained pellet was re suspended in $500 \mu \mathrm{L}$ FSW and the concen tration of MP and/or microalgae assessed microscopically (Axi oskop 40, Carl Zeiss, Milan, Italy; $40 \times$ magnification). The consumption of both administered items was assessed by measuring the percentage of concentration variations in the exposure medium with respect to control.

\subsection{Embryotoxicity and transcriptional effects of MP on mussel embryos}

\subsubsection{Experimental treatments}

Oocyte fertilization was performed in 6 well (mRNA expression) or 12 well (embryotoxicity test) plates as previously reported (Fabbri et al., 2014; Balbi et al., 2016). After $30 \mathrm{~min}$, fertilization success (n. fertilized eggs/n. total eggs $\times 100$ ) was verified microscopically $(>85 \%)$. The same concentration range tested for uptake assessment $\left(50,100,500,1,000,5000\right.$ and 10,000 $\mathrm{MP} \mathrm{mL}^{-1)}$ was used for the embryotoxicity test. For transcriptional analyses two concentrations in the low range tested for embryotoxicity (50 MP $\mathrm{mL}^{-1}$ and a $10 \mathrm{X}$ concentration, $500 \mathrm{MP} \mathrm{mL}^{-1}$ ) were chosen, based on the general assumption that functions at lower biological hierarchies, such as transcriptional pathways, are more sensitive and respond much faster to stress exposure than biological endpoints at higher biological hierarchies (Franzellitti et al., 2010). MP were added to each well at the selected nominal MP concentrations (for the embryotoxicity test; 50 and $500 \mathrm{MP} \mathrm{mL}^{-1}$ for mRNA expression analyses). A control treatment containing only FSW was simultaneously performed.

\subsubsection{Embryotoxicity test}

The embryotoxicity test was performed as described by Fabbri et al. (2014). After a $48 \mathrm{~h}$ incubation, samples were fixed with buffered formalin (4\%). All larvae in each well were examined by optical microscopy using an inverted microscope (OPTECH, IB series; Munchen, Germany; $40 \times$ magnification). Observations were carried out by an operator blind to the experimental conditions. A larva was considered normal when the shell was D shaped (straight hinge) and the mantle did not protrude out of the shell, and malformed if had not reached the stage typical for $48 \mathrm{~h} \mathrm{pf}$ (trocophore or earlier stages) or in the presence of developmental defects (concave, malformed or damaged shell, protruding mantle). The recorded endpoint was the mean \pm SEM ( $N$ 4) of the per centage of normal larvae ( $\mathrm{D}$ veligers). The acceptability of test results was based on controls for a percentage of normal D shell stage larvae $>70 \%$ (ASTM, 2004).

\subsection{3. mRNA expression by quantitative real time PCR ( $q P C R$ ) analysis}

Embryo handling and total RNA extraction was performed as described in detail by Balbi et al. (2016). RNA concentration and quality were verified using the Qubit RNA assay through the Qubit 2.0 system (Thermo Fisher, Milan, Italy) and electrophoresis using a $1.2 \%$ agarose gel under denaturing conditions. First strand cDNA for each sample was synthesized from $1 \mu \mathrm{g}$ total RNA using the iScript supermix (Bio Rad Laboratories, Milan, Italy) following manufacturer's instructions.

Gene transcription was evaluated in 4 independent RNA samples (about 6000 embryos/replicate). Primers pairs employed for qPCR analyses were as reported in previous studies or were designed with Primer Express (Thermo Fisher, Milan, Italy) using nucleotide sequences retrieved from the GeneBank database for $M$. galloprovincialis (Table S1). Reactions were performed in duplicate in a final volume of $10 \mu \mathrm{L}$ containing $5 \mu \mathrm{L}$ iTaq Universal master mix with ROX (BioRad Laboratories, Milan, Italy), $2 \mu \mathrm{L}$ diluted cDNA, and $0.2 \mu \mathrm{M}$ specific primers. A control lacking cDNA template (no template) and a minus reverse transcriptase (no RT) control were included in the qPCR analysis to determine the specificity of target cDNA amplifications. Amplifications were performed in a StepOne real time PCR system apparatus (Thermo Fisher, Milan, Italy) using a standard "fast mode" thermal protocol. For each target mRNA, melting curves and agarose gel electrophoresis were utilized to verify the specificity of the amplified products and the absence of artifacts. The amplification efficiency of each primer pair was calculated using a dilution series of cDNA (Table S1). Helicase and elongation factor $1 \alpha$ were selected as the best performing combi nation of reference gene products for qPCR data normalization through a preliminary stability analysis amongst 6 candidates (Balbi et al., 2016). Calculations of relative expression of target mRNAs was performed by a comparative $C_{T}$ method (Schmittgen and Livak, 2008) using the StepOne software tool (Thermo Fisher, Milan, Italy). Data were reported as relative expression $\left(\log _{2}\right.$ transformed fold change) compared to control samples.

\subsection{Data analysis}

After being tested for normality (Shapiro Wilk test) and variance homogeneity (Levene's mean test) data from uptake parameters, feeding behavior and embryotoxicity test were subjected to a 
one way ANOVA followed by Bonferroni multiple post hoc comparisons to test for significance amongst different treatments or between single treatments and control condition (SigmaPlot 13, Systat Software Inc. San Jose, CA, USA). Data from qPCR analyses were evaluated with the REST software (Pfaffl et al., 2002) that uses a randomisation test with a pairwise reallocation to assess the statistical significance of the differences in expression between each treatment group and the controls.

The putative occurrence of concentration dependent variations of MP uptake parameters, including the percentage of larvae showing ingestion of MP and the average number of ingested MP, was analysed by means of the Pearson correlation test. In addition, for all tested MP concentrations and larval age, the Pearson correlation coefficient was calculated to evaluate relationships between the percentage of larvae showing ingestion and the average num ber of ingested MP larva ${ }^{-1}$. In all approaches, $\mathrm{p}<0.05$ was set as the threshold level of statistical significance.

Additional permutation statistical approaches were used to evaluate:

i) Influences of MP concentrations on MP uptake at different post fertilization times. Data obtained from the analysis of the two uptake variables (i.e. the percentage of larvae showing ingestion and the average number of ingested MP larva ${ }^{-1}$ ) were submitted to a permutation multivariate analysis of variance (PERMA NOVA) using the PERMANOVA + add on in PRIMER v6 (Anderson et al., 2008). Standardized data were used to calculate similarity matrices based on the Euclidean distance (999 permutations). Factors were "larval development", represented by the tested post fertilization times ( 4 levels: 48 h, 3, 6 and 9d pf), and "treatment", referring to the tested MP concentrations (6 levels: 50, 100, 500, 1,000, 5,000, and 10,000 $\mathrm{MP} \mathrm{mL}^{-1}$ ). Pseudo $F$ values in the PERMANOVA main tests were evaluated in terms of significance $(P<0.05)$. When the main test revealed statistical differences, PERMANOVA pairwise comparisons were carried out (using the Euclidean distance matrix and 999 permutations).

ii) Interactive effects of MP treatment on transcript expressions across embryo development. Relative expression data from MP treatments at different post fertilization periods were submitted to PERMANOVA analysis using the PERMANOVA + add on in PRIMER v6. $\log _{2}$ transformed fold change variations of the target transcripts were used to calculate similarity matrices based on the Euclidean distance (999 permutations). Factors were "developmental stage" and "treatment". Numerical metric for life stage progression was indicated by the post fertilization time $(0,24,48 \mathrm{~h})$. Treatment was indicated by the nominal MP concentrations of exposure $\left(0,50\right.$, and 500 particles $\left.\mathrm{mL}^{-1}\right)$. Pseudo $F$ values in the PERMANOVA main tests were evaluated in terms of significance $(\mathrm{P}<0.05)$. Distance based redundancy linear modeling (DISTLM) followed by a redundancy analysis (dbRDA) in PRIMER was also performed to examine the relationship between the multivariate dataset (i.e. the suite of transcripts assayed and their expression levels) and the pre dictor variables (developmental stage and MP treatment). DISTLM used the BEST selection procedure and adjusted $\mathrm{R}^{2}$ selection criteria.

\section{Results}

\subsection{Uptake assessment}

According to the PERMANOVA (Table S2), factors "MP concentration" and "time post fertilization", as well as their interaction, had a significant effect on the overall MP uptake levels. The
PERMANOVA pairwise comparisons (Table S3) revealed significant differences between MP uptake levels at $48 \mathrm{~h}$ pf and those recorded at 3, 6, $9 \mathrm{~d}$ pf for all performed treatments. Larvae exposed at $3 \mathrm{~d} \mathrm{pf}$ showed significant differences compared to $6 \mathrm{~d}$ pf at 500-10,000 $\mathrm{MP} \mathrm{mL} L^{-1}$, as well as to $100-5000 \mathrm{MP} \mathrm{mL}^{-1}$ when compared to $9 \mathrm{~d}$ pf. Levels measured at 6 and $9 \mathrm{~d}$ pf significantly differed each other in the presence of 100 and $10,000 \mathrm{MP} \mathrm{mL}^{-1}$.

Levels of MP uptake by mussel larvae tended to increase with increasing concentrations (Fig. S1 A-D). At all tested post fertilization periods, the exposure to $50-10,000 \mathrm{MP} \mathrm{mL}^{-1}$ resulted in significant increases of both the percentage of larvae showing MP ingestion (Fig. 1A-D) and the number of ingested particles (Fig. $1 \mathrm{E}-\mathrm{H})$. However, only at $48 \mathrm{~h}, 3$ and $6 \mathrm{~d}$ pf the levels of both parameters were significantly and positively correlated to the nominal MP concentrations, while no significant relationship was noted at $9 \mathrm{~d}$ pf. The lowest uptake levels and variations among treatments were showed by larvae at $48 \mathrm{~h}$ pf, in which significant increases of both parameters were detected only at the highest tested concentration (Fig. 1A, E). Major changes in the number of ingested MP were detected at $6 \mathrm{~d}$ pf, with levels reaching up to 14.2 MP larva ${ }^{-1}$ at $10,000 \mathrm{MP} \mathrm{mL}^{-1}$ (Fig. 1G) The only significant decrease in the number of ingested MP with increasing concentration was detected in larvae at $9 \mathrm{~d}$ pf exposed to $10,000 \mathrm{MP} \mathrm{mL}^{-1}$ compared to $5000 \mathrm{MP} \mathrm{mL}^{-1}$ (Fig. $1 \mathrm{H}$ ). At all post fertilization periods, the percentage of larvae showing MP ingestion was significantly and positively correlated with the average number of ingested MP larva ${ }^{-1}$ (Fig. S2). The analysis in epifluorescence microscopy did not highlight MP aggregation or plate wall adherence after $24 \mathrm{~h}$ of suspension.

\subsection{Evaluation of MP retention time and effects on food consumption}

Results of the MP retention assessment performed on larvae exposed to MP for $24 \mathrm{~h}$ are shown in Fig. 2. Larvae were exposed to a concentration of $1000 \mathrm{MP} \mathrm{mL}^{-1}$ leading to an average accumulation lower than $10 \mathrm{MP} \mathrm{larva}^{-1}$ (based on uptake information reported in Fig. 1E-H), thus avoiding the possible effect of a high gut load on the subsequent elimination of ingested particles. At the end of the exposure period, $92 \%$ of exposed larvae showed ingested MP. A remarkable egestion was observed at $24 \mathrm{~h}$ from exposure, when only $23 \%$ of D veligers showed ingested MP. A further drop to $9.1 \%$ was recorded after the following $24 \mathrm{~h}$, while fluctuations in the $3-10 \%$ range were noted in subsequent observations. The experiment was stopped at $204 \mathrm{~h}$ ( 8.5 days) from exposure, time at which all examined larvae showed no MP for two consecutive intervals. No mortality of larvae was registered during the test.

The co exposure to $2000 \mathrm{MP} \mathrm{mL}^{-1}$ and 2000 cell $\mathrm{mL}^{-1}$ of the microalga $N$. oculata revealed a significant preference for nutritious items (algae) by mussel larvae, which consumed the $80 \%$ of administered cells vs the $20 \%$ of MP (Fig. 3). Similar results were obtained in single exposures, in which algae consumption was significantly higher (87\%) compared to MP (about $40 \%$ ) after $24 \mathrm{~h}$ of exposure. The consumption of both MP and $N$. oculata did not change significantly between single and co exposure treatments.

\subsection{Embryotoxicity test}

Results of the embryotoxicity test performed on $M$. galloprovincialis embryos exposed to MP (50-10,000 particle $\mathrm{mL}^{-1}$ ) are shown in Fig. 4 . At $48 \mathrm{~h}$ pf the $86.2 \pm 4.7 \%$ of normally developed D shape veligers was noted in control samples, thus achieving requirements for test acceptance ( $\geq 75 \%$; Fabbri et al., 2014). Compared to control, no significant decreases in the fra tion of normally developed D shape larvae were observed in 
$\begin{array}{llll}48 \mathrm{~h} \mathrm{pf} & 3 \mathrm{~d} \mathrm{pf} & 6 \mathrm{~d} \mathrm{pf} & 9 \mathrm{~d} \mathrm{pf}\end{array}$
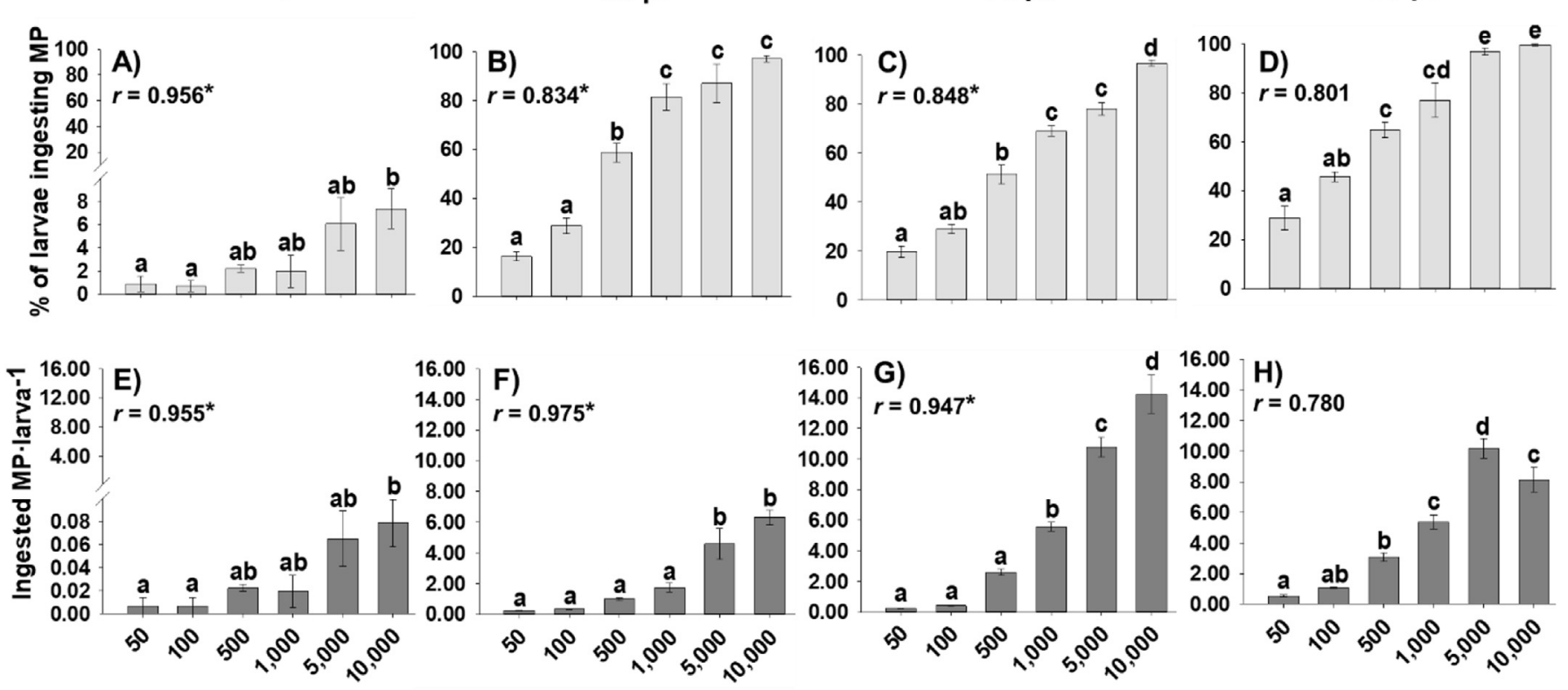

$$
\mathrm{MP} \cdot \mathrm{mL}^{-1}
$$

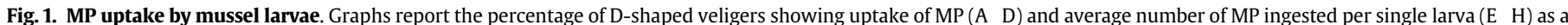

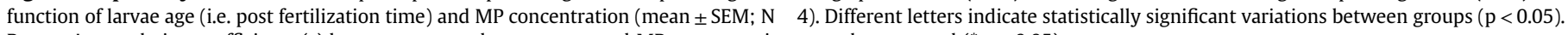
Pearson's correlation coefficients $(r)$ between assessed parameters and MP concentrations are also reported $\left({ }^{*} \mathrm{p}<0.05\right)$.

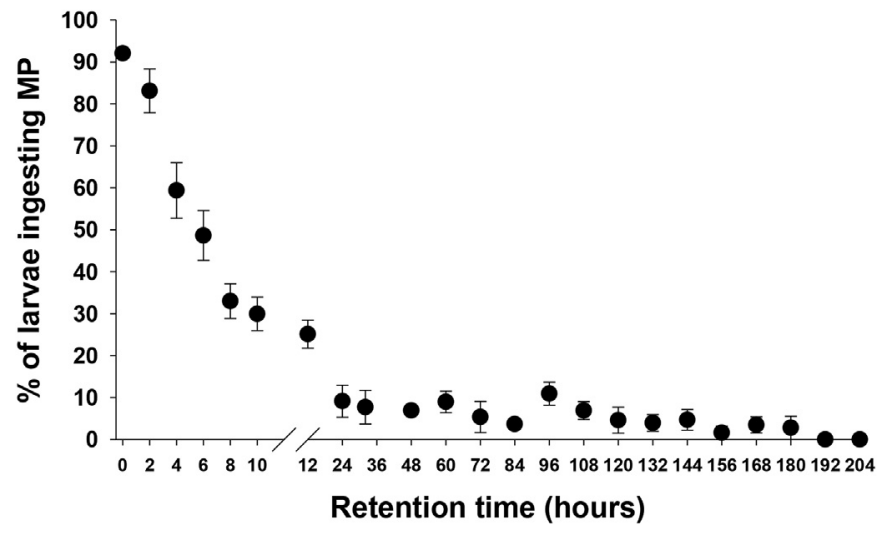

Fig. 2. Time employed for MP egestion by mussel larvae. Experiments were performed on $6 \mathrm{~d}$ pf larvae exposed for $24 \mathrm{~h}$ to $1000 \mathrm{MP} \mathrm{mL}{ }^{1}$ and transferred to clean FSW for different post-exposure periods. Observations were performed until samples at two consecutive time points showed no larvae with ingested MP. Data are reported as mean \pm SEM $(\mathrm{N} 4)$ of the percentage of larvae showing MP uptake.

samples grown in the presence of increasing MP concentrations.

\subsection{Effects of MP on gene transcription}

Treatments with polystyrene MP induced overall up regulation of immune related gene products in D veligers (48 h pf), in particular of $L Y S$ at $500 \mathrm{MP} \mathrm{mL}^{-1}$, and of MYTC and MYTLB at 50 and $500 \mathrm{MP} \mathrm{mL}^{-1}$ (Fig. 5A). Transcripts encoding lysosomal enzymes were differently regulated at the tested nominal MP concentrations, with GUSB being significantly down regulated at both tested MP concentrations, HEX being down regulated at $50 \mathrm{MP} \mathrm{mL} L^{-1}$, and CTSL being significantly up regulated at $500 \mathrm{MP} \mathrm{mL}^{-1}$ (Fig. 5B). As to neuroendocrine related transcripts, significant up regulation of the 5 HT1 gene product was observed in D veligers at $500 \mathrm{MP} \mathrm{mL}{ }^{-1}$,

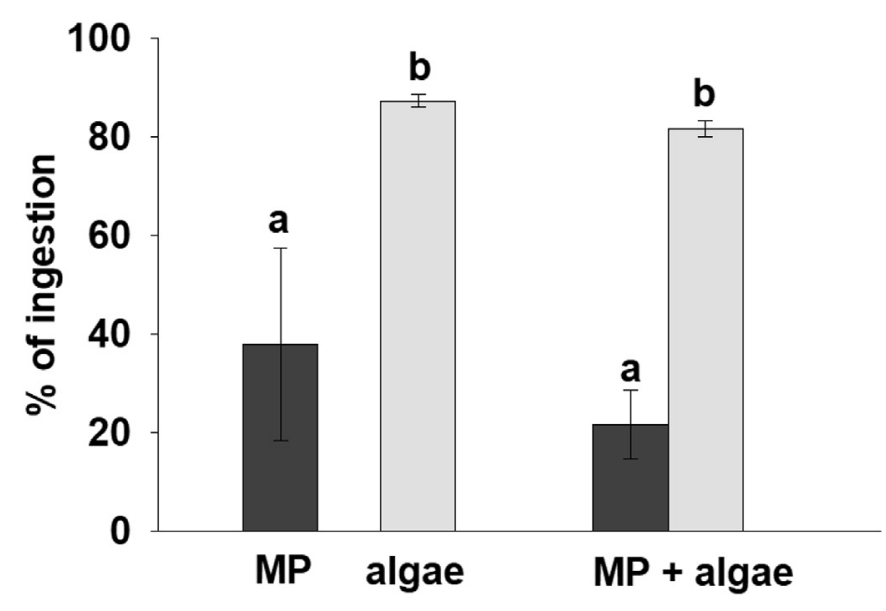

Fig. 3. Effects of polystyrene MP $(3 \mu \mathrm{m})$ on the consumption of microalgae ( $N$. oculata, $25 \mu \mathrm{m}$ ) by mussel larvae. Single exposure treatments consisted of a 24-h exposure to $2000 \mathrm{MP} \mathrm{mL}{ }^{1}$ or 2000 algae $\mathrm{mL}^{1}$. Co-exposure treatment consisted of a 24-h exposure to a mixture of 2000 cell $\mathrm{mL}^{1}$ and $2000 \mathrm{MP} \mathrm{mL}{ }^{1}$. Data represent the percentage of MP or algae consumed by mussel larvae (mean \pm SEM; $N \quad 4$ ). Different letters indicate statistically significant differences $(\mathrm{p}<0.05)$.

while levels of MeER1 and MeER2 transcripts resulted unchanged (MeER1) or differently regulated (MeER2: significant up regulation at $50 \mathrm{MP} \mathrm{mL}^{-1}$ and down regulation at $500 \mathrm{MP} \mathrm{mL}^{-1}$ ) (Fig. 5C). CA, CS, and $E P$ transcripts involved in shell biogenesis were signif icantly up regulated at $500 \mathrm{MP} \mathrm{mL}^{-1}$ (Fig. 5D). Finally, mRNA levels of MT10 and MT20 methallotionein gene products (here considered as involved in ROS scavenging/antioxidant processes) were unchanged (MT10) or significantly up regulated (MT20) at $500 \mathrm{MP} \mathrm{mL}^{-1}$ (Fig. $5 \mathrm{E})$.

A multivariate permutation statistical approach was used to infer the putative interactive effects of MP treatment on the observed transcript expressions across embryo development. The 


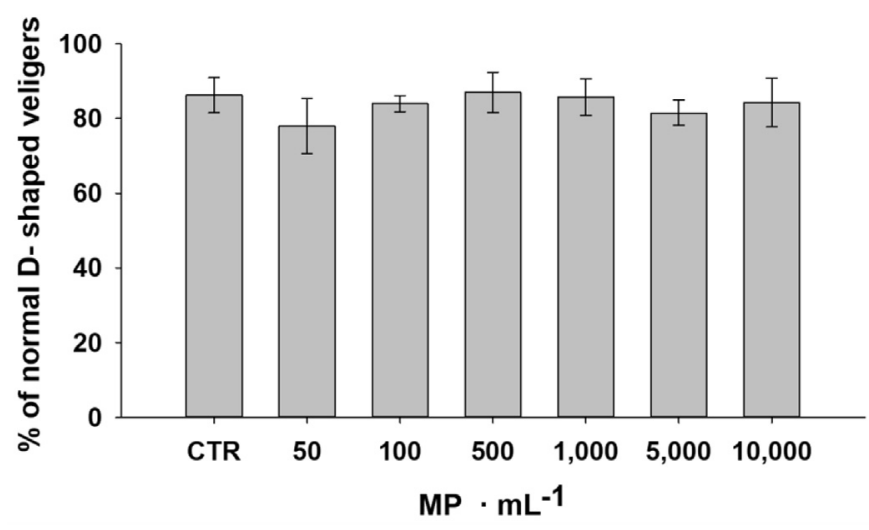

Fig. 4. Effects of $3 \mu \mathrm{m}$ polystyrene MP on $M$. galloprovincialis normal embryo-larval development in the 48-h embryotoxicity assay. Data represent the mean \pm SEM (N 4) of the percentage of normal D-shaped larvae at each treatment. No statistically significant differences $(\mathrm{p}<0.05)$ were observed between treatments and control.

employed dataset comprised levels for the target transcripts in unfertilized eggs and their variations at $24 \mathrm{~h} \mathrm{pf}$ (Fig. S3), other than those at $48 \mathrm{~h}$ pf reported in Fig. 5A-E. PERMANOVA analyses demonstrated a significant effect of MP treatment on gene transcription and a significant interaction with embryo development (Table S4). Indeed, distance based linear model (DISTLM) analysis revealed that though expression profiles were strongly dependent on embryo development (explaining about $84 \%$ total variation), MP treatment accounted for about $8 \%$ of total variation, which mostly explained the observed changes in transcript expressions at $48 \mathrm{~h} \mathrm{pf}$ (Fig. 5F). DISTLM ordination analysis by functional group revealed that expression patterns of transcripts involved in shell biogenesis, lysosomal response, and immune responses mostly explained the observed MP effects at $48 \mathrm{~h}$ pf, while effects on antioxidant responses and neuroendocrine signaling peaked at earlier develop mental stages (Fig. 5G).

\section{Discussion}

The emerging paradigm about plastic pollution of marine en vironments is that micro to nano size particles may have far more subtle effects compared to bigger litter fragments, since their size range overlaps with the preferred particle size ingested by marine zooplankton (reviewed by Galloway and Lewis, 2016). In marine and freshwater copepods, nanoplastics and microplastics have been associated to reduced feeding and sub lethal health outcomes (Cole et al., 2015; Lee et al., 2013; Besseling et al., 2014). Aimed at providing further insights, the present study evaluated the poten tial for $3 \mu \mathrm{m}$ polystyrene MP to be ingested by larvae of $M$. galloprovincialis, measured the dynamics of MP uptake as a function of larvae development and particle concentration, and assessed the potential physiological adverse outcomes of MP ingestion at the morphological (48 h embryotoxicity assay) and molecular (transcriptional effects) levels. Employed MP were selected to closely match size range $(2-6 \mu \mathrm{m})$ and shape (spherical) of phytoplanktonic species known as food sources for mussel larvae (Widdows, 1991).

Previous investigations were performed using the same typology of polystyrene microspheres to assess the impact of MP or nanoplastics on marine taxa, including phytoplankton (Long et al., 2017), crustaceans (Jeong et al., 2017) and molluscs (Paul Pont et al., 2016). Data obtained in this study showed that MP were readily ingested by mussel larvae, with uptake rates positively correlated with MP concentration and larvae development. Sprung (1984) found that within a range of $0-10,000$ cells $\mathrm{mL}^{-1}$ of the alga Isochrysis galbana, mussel larvae adapt ingestion rate to the external food availability, suggesting that a similar feed back regulation may occur in response to increasing MP concentrations.

At our experimental conditions, a lower ingestion was observed in $48 \mathrm{~h}$ pf larvae compared to elder specimens (3-9 d pf). Conversely, no significant changes in MP uptake propensity were found in larvae of the sea urchin T. gratilla at $1-5 \mathrm{~d}$ pf (Kaposi et al., 2014). This points out the possible influence of different developmental timing of the filter feeding behavior between the larval stages of the two species. In fact, relevant neuro myogenic events occur in mussel larvae between 48 and $60 \mathrm{~h} \mathrm{pf}$, resulting in the functional differentiation of the velum retractor muscles involved in particle catching and ingestion (Dyachuck and Odintsova, 2009). According to the PERMANOVA, MP concentrations higher than 50 particles $\mathrm{mL}^{-1}$ induced significantly different trends of uptake between larvae at $3 \mathrm{~d}$ pf and those at 6-9 d pf. All larvae showed similar propensities to the ingestion (>95\% larvae ingesting MP at $10,000 \mathrm{MP} \mathrm{mL}^{-1}$ ), while increasing concentrations caused a higher MP accumulation in 6-9 d pf larvae compared to younger specimens, in line with trends previously observed in oyster larvae (3-24 d pf) exposed to increasing MP size (Cole and Galloway, 2015).

Interestingly, a lower MP accumulation was noted at $9 \mathrm{~d}$ pf in larvae exposed to the highest tested concentration $(10,000 \mathrm{MP}$ $\mathrm{mL}^{-1}$ ). Such response may be the consequence of growth related variations of swimming/feeding behavior in rela tion to the particles availability. According to Cragg (1980), as the shell weight/size increase, bivalve larvae alternate active to passive periods passed on the substrate, resulting in a prolonged static filtration and a lower uptake rate at higher concentrations of microalgae. Therefore, the interaction between MP and planktonic larvae might be influenced by their progressive morpho functional development (e.g. from free swimming to sessile behavior), ultimately leading to changes in uptake trends. It is important to consider that MP concentrations employed in this far exceeded those detected in the marine environment, which range from 0.01 particles per $\mathrm{m}^{3}$ (GESAMP, 2016) to 102,000 particles per $\mathrm{m}^{3}$ seawater (Norèn, 2007). However, since levels of marine contamination by plankton sized MP are thought to increase for effect of weathering (Anderson et al., 2016; Lusher, 2015), obtained findings provide reliable clues on the associated enhancement of uptake by marine larvae.

MP retention experiments showed that about $80 \%$ of analysed larvae egested MP within $24 \mathrm{~h}$ from exposure. However, $192 \mathrm{~h}$ (8 days) were necessary to achieve gut clearance in $100 \%$ individuals, suggesting that, although in the same size range of microalgae, MP do not easily pass the larvae digestive tract. Differently, pluteus larvae from the sea urchin $T$. gratilla showed a fast elimination of polyethylene MP, with the $100 \%$ egestion achieved after $480 \mathrm{~min}$ from exposure (Kaposi et al., 2014). Such discrepancy could reflect the distinct morpho structural features characterizing the gastrointestinal tract of mussel veligers and sea urchin plutei (Aranda Burgos et al., 2014; Rahman et al., 2012), likely resulting in a more efficient elimination route displayed by sea urchins. Intestinal stasis of MP is a hazardous condition for the organism fitness, with effects spanning from reduced nutritional status and energy storage to severe digestive blockage (Grigorakis et al., 2017). A further concern associated to a prolonged gut retention relies on the finding that MP may act as a vehicle for the ingestion of chemical or microbiological agents. Modeling studies demonstrated that the transfer of organic pollutants sorbed onto plastics is of limited importance compared to other routes of exposures (Bakir et al., 2016; Koelmans et al., 2016). However, the role of MP as vectors of pathogens has recently been confirmed (Lamb et al., 2018) and 

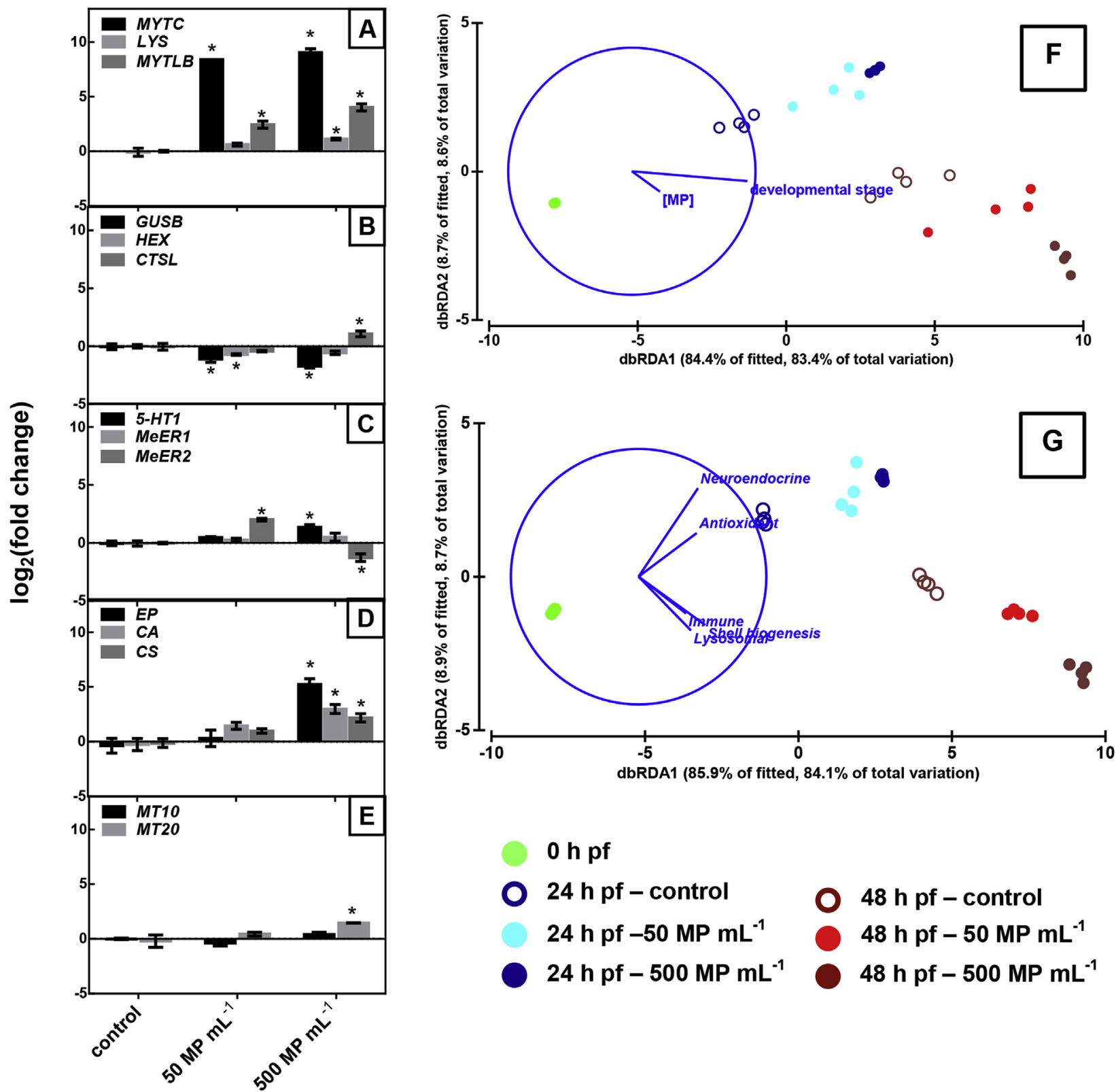

h pf

O 24 h pf - control

$24 \mathrm{~h} \mathrm{pf}-50 \mathrm{MP} \mathrm{mL}^{-1}$

$24 \mathrm{~h}$ pf $-500 \mathrm{MP} \mathrm{mL}^{-1}$

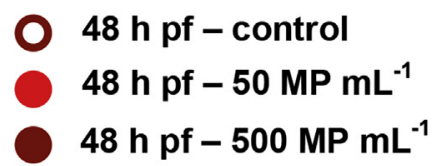

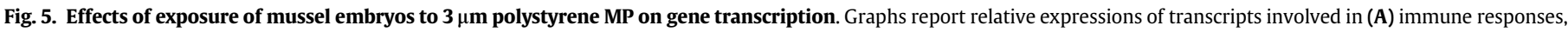

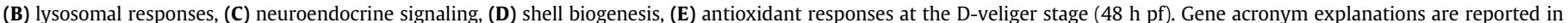

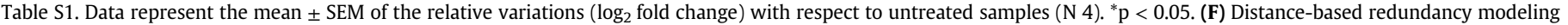

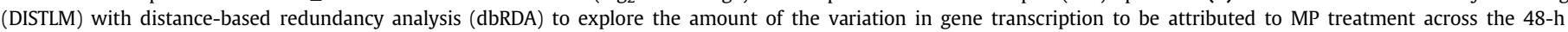

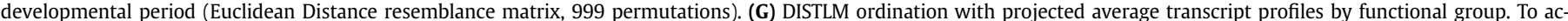

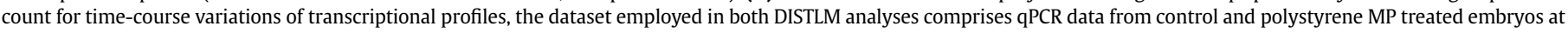
$24 \mathrm{~h}$ pf and $48 \mathrm{~h}$ pf compared to unfertilized oocytes $(0 \mathrm{~h}$ pf.

growing concerns are expressed on the risks posed by the leakage of additives from ingested MP (Revel et al., 2018).

Impairment of feeding efficiency is one of the most concerning issues related to the occurrence of MP in marine environments (Galloway et al., 2017). In this study we showed that the presence of MP did not affect the average consumption of $N$. oculata algae by mussel larvae. This may indicate that, though apparently equipped with a rudimentary feeding apparatus, mussel D veligers may ex press food preferences by selectively preying on planktonic items of relatively high nutritional value, as it occurs in adults (Ward and Shumway, 2004). This finding also suggests that polystyrene MP may have a low chemotactile attractiveness for larvae compared to nutritious particles. Kaposi et al. (2014) reported that presence of biofouling on polyethylene microspheres reduced their ingestion by $T$. gratilla larvae. Although a specific investigation on this issue was out of the scope of our work, it has to be acknowledged that in the framework of environmentally realistic scenarios, MP properties can be modified due to de sorption of organic compounds or adsorption of biomolecules from biological fluids (e.g. proteins and/ or polysaccharides), thus forming an eco/bio corona (Canesi and Corsi, 2016). As discussed by Galloway et al. (2017), this could strongly influence the interaction of MP with cells and tissues, and ultimately their bioavailability, persistence and toxicity.

No significant increase in the occurrence of macroscopical 
abnormalities was noted in mussel embryos grown for $48 \mathrm{~h}$ pf in the presence of $50-10,000 \mathrm{MP} \mathrm{mL}^{-1}$, thus apparently suggesting no relevant interactions of tested MP with normal larval development. When converted to particle weight volume ${ }^{-1}$ values, the tested MP concentrations were $0.8-154 \mu \mathrm{g} \mathrm{L}^{-1}$, a range of values partially overlapping that employed by Balbi et al. (2017), where significant embryotoxicity effects were found in $48 \mathrm{~h}$ pf mussel $\mathrm{D}$ veligers in the presence of $50 \mathrm{~nm}$ amino polystyrene MP (0.001-20 mg/L). The differences in MP size may explain such discrepancy. Indeed, par ticles smaller than $100 \mathrm{~nm}$ were showed to be more efficiently accumulated by marine zooplankton, to have longer retention times, and to display unique properties that may enhance their toxicity (Canesi and Corsi, 2016; Cole and Galloway, 2015; Bouwmeester et al., 2015). Moreover, as discussed by Mazurais et al.(2015) and Sussarellu et al. (2016), spherical microparticles may display a lower impact on larvae with respect to plastic fibers or rough fragments, which are the most frequently detected MP in the marine environment. In fact, Ziajahromi et al. (2017) recently re ported that polyester fibers induce higher adverse effects than polyethylene microbeads on the survival, growth and reproduction of the waterflea Ceriodaphnia dubia.

Despite the lack of relevant morphological effects, qPCR data reported in this study did show interaction of MP exposure with transcriptional regulation of several genes involved in different physiological processes across the $48 \mathrm{~h}$ pf period. Among these, transcripts related to immune responses, shell biogenesis, and lysosomal responses were the most affected by MP exposure of embryos. The development of the immune system is inextricably linked with the formation of the digestive system in bivalves, and at the early larval stages the immune cells are believed to act as digestive system cells (Dyachuk, 2016; Balseiro et al., 2013). Furthermore, in adult bivalves, a molecular evolution of immune related proteins from defense to digestive functions has been postulated (Jollès et al., 1996), leading these proteins to be also expressed in the digestive gland and other tissues (Wang et al., 2012; Balbi et al., 2014). Therefore, the over expression observed for the immune related transcripts LYS, MYTC and MYTLB may result from the uptake activity displayed by $\mathrm{D}$ veligers towards MP, and the consequent stimulation of the digestive/immune apparatus.

Transcripts involved in shell biogenesis were significantly up regulated at $500 \mathrm{MP} \mathrm{mL}$. Previous evaluations across the $48 \mathrm{~h}$ embryo development under normal growing conditions showed the selected transcript expressions to be highest at $48 \mathrm{~h} \mathrm{pf}$, confirming their key role in initial shell deposition (Balbi et al., 2016, 2017). In general, carbonic anhydrase (CA) regulates matrix mineralization by generating an acidic environment at the calcification sites (Clark et al., 2010); the mussel extrapallial protein (EP) regulates the production of the different polymorphs of calcium carbonate (Yin et al., 2009), and chitin synthase (CS) catalyzes the synthesis of chitin, a key structural component of the shell matrix that drives initial calcium carbonate deposition (Schonitzer and Weiss, 2007; Weiss and Schonitzer, 2006). Though the down regulation of these transcripts were previously reported in D veligers showing gross shell malformations and reduced calcification (Balbi et al., 2016, 2017), their up regulations observed in this study may boost the molecular machinery responsible for calcium carbonate fixation $(C A, E P)$ and organic matrix functions $(C S)$, thus explaining the apparent lack of effects of MP in the embryotoxicity test.

A significant down regulation of transcripts encoding the lyso somal enzymes hexosaminidase (HEX), $\beta$ glucorinidase (GUSB), and cathepsin L (CTSL) was observed at both tested MP concentrations in $48 \mathrm{~h}$ D veligers. Dysfunctional effects on lysosomes were previously observed in digestive glands and haemocytes of adult mussels exposed in vivo to polyethylene and polystyrene MP (Avio et al., 2015; von Moos et al., 2012). These investigations showed significant reduction of lysosomal enzyme stability in both immune and digestive tissues as related to MP accumulation within the organelles and the induction of an inflammatory response (Avio et al., 2015; von Moos et al., 2012). To the best of our knowledge, though based on transcriptional data, the present study is the first reporting the onset of a lysosomal dysfunctional response in larval stages of mussels. It must be observed that Izagirre et al. (2014) reported concomitant HEX, GUSB, CTSL down regulation, and decreased lysosomal membrane stability in digestive glands of adult mussels exposed to thermal stress and $\mathrm{Cd}^{2+}$. The authors suggested that such an apparent down regulation might result from genotoxic effects caused by Cd but also from molecular degeneration and loss of lysosomal functionality.

\section{Conclusions}

Data reported in this study showed that mussel larvae can effectively ingest and accumulate polystyrene MP, suggesting their potential role as plastic primary consumers in marine ecosystems. MP ingestion took place from the very early larval stage, and up take/accumulation levels showed a linear relationship with the particle concentrations and the larvae morphological development up to $6 \mathrm{~d}$ pf. The consumption of microalgae by mussel larvae was not affected by the co occurrence of MP, suggesting that their impacts on exposed organisms could be limited by their ability to discriminate among nutritious and non food items. On the other hand, larvae showed a prolonged MP gut retention. The long lasting presence of non nutritious particles in the gut is per se associated to adverse biological impacts for the individuals, thus leading to consider mussel early life stages as particularly subjected to the effects of MP pollution; further, retained particles will more likely be accessible to higher trophic levels. Although no consistent effects on the morphological development were observed, transcriptional data obtained in this study outline the potential impacts of MP on shell biogenesis, immune and lysosomal systems.

The present investigations were performed using spherical polystyrene MP in controlled laboratory conditions; thus, observed responses might not necessarily reproduce those occurring in natural systems, where organisms are simultaneously exposed to a broad range of structurally heterogeneous MP of irregular shape/ size and further associated stressors. Nevertheless, data highlight the vulnerability of bivalve early life stages towards MP, providing baseline information for future investigation addressing their impact on marine ecosystems.

\section{Acknowledgements}

This work has been funded by the EU project PLASTOX (Direct and indirect ecotoxicological impacts of microplastics on marine organisms), which is part of the Joint Programming Initiative Healthy and Productive Seas and Oceans (JPI OCEANS - CSA OCEANS 2; grant agreement No 696324). M. Capolupo has been supported by the grant provided by the Erasmus Mundus PhD Programme in Marine and Coastal Management (MACOMA SGA No. 2014 0693/001 001 EMJD). The Authors are grateful to Prof. Rossella Pistocchi and collaborators for the technical assistance provided for analyses performed on epifluorescence microscopy. The Authors declare that there are no conflicts of interest regarding the publication of this paper.

\section{Appendix A. Supplementary data}

Supplementary data related to this article can be found at 
https://doi.org/10.1016/j.envpol.2018.06.035.

\section{References}

Anderson, J.C., Park, B.J., Palace, V.P., 2016. Microplastics in aquatic environments: implications for Canadian ecosystems. Environ. Pollut. 218, 269 280. https:// doi.org/10.1016/j.envpol.2016.06.074.

Anderson, M., Gorley, R., Clarke, K., 2008. PERMANOVA+ for PRIMER. Guide to Software and Statistical Methods. PRIMER-E Ltd., Plymouth, U.K, p. 214. Andrady, A.L., 2011. Microplastics in the marine environment. Mar. Pollut. Bull. 62, 1596 1605. https://doi.org/10.1016/j.marpolbul.2011.05.030.

Aranda-Burgos, J.A., Da Costa, F., Novoa, S, Ojea, J., Martinez-Patino, D., 2014. Em-
bryonic and larval development of Ruditapes decussatus (Bivalvia : Veneridae): a study of the shell differentiation process. J. Molluscan Stud. 80, 8 16. https:// doi.org/10.1093/mollus/eyt044.

ASTM, 2004. Standard Guide for Conducting Acute Toxicity Test Starting with Embryos of Four Species of Saltwater Bivalve Molluscs. E 724 98, p. 21. https:// doi.org/10.1520/E0724-98R12.2.

Avio, C.G., Gorbi, S., Regoli, F., 2017. Plastics and microplastics in the oceans: from emerging pollutants to emerged threat. Mar. Environ. Res. 128, 2 11. https:// doi.org/10.1016/j.marenvres.2016.05.012.

Avio, G.C., Gorbi, S., Milan, M., Benedetti, M., Fattorini, D., Pauletto, M., Bargelloni, L., Regoli, F., 2015. Pollutants bioavailability and toxicological risk from micro-plastics to marine mussels. Environ. Pollut. 198, 211 222. https:// doi.org/ 10.1016/j.envpol.2014.12.021.

Bakir, A., O'Connor, I.A., Rowland, S.J., Hendriks, A.J., Thompson, R.C., 2016. Relative importance of microplastics as a pathway for the transfer of hydrophobic organic chemicals to marine life. Environ. Pollut. 219, 56 65. https://doi.org/ 10.1016/j.envpol.2016.09.046

Balbi, T., Camisassi, G., Montagna, M., Fabbri, R., Franzellitti, S., Carbone, C., Dawson, K., Canesi, L., 2017. Impact of cationic polystyrene nanoparticles (PS- $\mathrm{NH}_{2}$ ) on early embryo development of Mytilus galloprovincialis: effects on shell formation. Chemosphere 186, 1 9. https://doi.org/10.1016/ j.chemosphere. 2017.07.120.

Balbi, T., Franzellitti, S., Fabbri, R., Montagna, M., Fabbri, E., Canesi, L., 2016. Impact of bisphenol A (BPA) on early embryo development in the marine mussel Mytilus galloprovincialis: effects on gene transcription. Environ. Pollut. 218, 9961004. https://doi.org/10.1016/j.envpol.2016.08.050

Balbi, T., Smerilli, A., Fabbri, R., Ciacci, C., Montagna, M., Grasselli, E., Brunelli, A., Pojana, G., Marcomini, A., Gallo, G., Canesi, L., 2014. Co-exposure to n-TiO 2 and $\mathrm{Cd}_{2}+$ results in interactive effects on biomarker responses but not in increased toxicity in the marine bivalve M. galloprovincialis. Sci. Total Environ. 493, 355 364. https://doi.org/10.1016/j.scitotenv.2014.05.146.

Balseiro, P., Moreira, R., Chamorro, R., Figueras, A., Novoa, B., 2013. Immune responses during the larval stages of Mytilus galloprovincialis: metamorphosis alters immunocompetence, body shape and behavior. Fish Shellfish Immunol. 35, 438 447. https://doi.org/10.1016/j.fsi.2013.04.044

Besseling, E., Wang, B., Lu, M., Koelmans, A.A., 2014. Nanoplastic affects growth of $S$. obliquus and reproduction of D. magna. Environ. Sci. Technol. 48, 12336 12343. https://doi.org/10.1021/es503001d.

Bouwmeester, H., Hollman, P.C., Peters, R.J., 2015. Potential health impact of environmentally released micro-and nanoplastics in the human food production chain: experiences from nanotoxicology. Environ. Sci. Technol. 49, 8932 8947. https://doi.org/10.1021/acs.est.5b01090.

Canesi, L., Corsi, I., 2016. Effects of nanomaterials on marine invertebrates. Sci. Total Environ. 565, 933 940. https://doi.org/10.1016/j.scitotenv.2016.01.085.

Clark, M.S., Thorne, M.A., Vieira, F.A., Cardoso, J.C., Power, D.M., Peck, L.S., 2010 Insights into shell deposition in the Antarctic bivalve Laternula elliptica: gene discovery in the mantle transcriptome using 454 pyrosequencing. BMC Genom. 11, 362. https://doi.org/10.1186/1471-2164-11-362.

Cole, M., Galloway, T.S., 2015. Ingestion of nanoplastics and microplastics by pacific oyster larvae. Environ. Sci. Technol. 49, 14625 14632. https:// doi.org/10.1021/acs.est.5b04099.

Cole, M., Lindeque, P., Fileman, E., Halsband, C., Galloway, T.S., 2015. The impact of polystyrene microplastics on feeding, function and fecundity in the marine copepod Calanus helgolandicus. Environ. Sci. Technol. 49, 1130 1137. https:// doi.org/10.1021/es504525u.

Cragg, S.M., 1980. Swimming behaviour of the larvae of Pecten maximus ( 1.) ( Bivalvia ). J. Mar. Biol. Assoc. U. K. 60, 551 564. https:// doi.org/10.1017/S002531540004025X.

Derraik, J.G., 2002. The pollution of the marine environment by plastic debris: a review. Mar. Pollut. Bull. 44, 842 852. https://doi.org/10.1016/ S0025-326X(02) 00220-5.

Dyachuk, V.A., 2016. Hematopoiesis in Bivalvia larvae : cellular origin, differentiation of hemocytes, and neoplasia. Dev. Comp. Immunol. 65, 253257. https://doi.org/10.1016/j.dci.2016.07.019.

Dyachuk, V., Odintsova, N., 2009. Development of the larval muscle system in the mussel Mytilus trossulus (Mollusca, Bivalvia). Dev. Growth Differ. 51, 69 79. https://doi.org/10.1111/j.1440-169X.2008.01081.x.

Eriksen, M., Lebreton, L.C.M., Carson, H.S., Thiel, M., Moore, C.J., Borerro, J.C., Galgani, F., Ryan, P.G., 2014. Plastic pollution in the World' s Oceans : more than 5 trillion plastic pieces weighing over 250,000 tons afloat at sea. PLoS One 9, 1 15. https://doi.org/10.1371/journal.pone.0111913 e111913.

Fabbri, R., Montagna, M., Balbi, T., Raffo, E., Palumbo, F., Canesi, L., 2014. Adaptation of the bivalve embryotoxicity assay for the high throughput screening of emerging contaminants in Mytilus galloprovincialis. Mar. Environ. Res. 99, 18. https://doi.org/10.1016/j.marenvres.2014.05.007.

Franzellitti, S., Buratti, S., Donnini, F., Fabbri, E., 2010. Exposure of mussels to a polluted environment: insights into the stress syndrome development. Comp. Biochem. Physiol. C Toxicol. Pharmacol. 152, 24 33. https://doi.org/10.1016/ j.cbpc.2010.02.010.

Galloway, T.S., Cole, M., Lewis, C., 2017. Interactions of microplastic debris throughout the marine ecosystem. Nat. Publ. Gr. 1, 1 8. https://doi.org/10.1038/ s41559-017-0116.

Galloway, T.S., Lewis, C.N., 2016. Marine microplastics Spell Big Problems for Future Generations, vol. 113, pp. 2331 2333. https://doi.org/10.1073/pnas.1600715113. GESAMP, 2016. Sources, fate and effects of microplastics in the marine environment: part two of a global assessment. In: Kershaw, P.J., Rochman, C.M. (Eds.), IMO/FAO/UNESCO-IOC/UNIDO/WMO/IAEA/UN/UNEP/UNDP Joint Group of Experts on the Scientific Aspects of Marine Environmental Protection). Rep. Stud. GESAMP No. 93, p. 220.

Grigorakis, S., Mason, S.A., Drouillard, K.G., 2017. Determination of the gut retention of plastic microbeads and microfibers in gold fish (Carassius auratus). Chemo-

sphere 169, 233 238. https://doi.org/10.1016/j.chemosphere.2016.11.055. Izagirre, U., Errasti, A., Bilbao, E., Múgica, M., Marigómez, I., 2014. Combined effects of thermal stress and Cd on lysosomal biomarkers and transcription of genes encoding lysosomal enzymes and HSP70 in mussels, Mytilus galloprovincialis. Aquat. Toxicol. 149, 145 156. https://doi.org/10.1016/j.aquatox.2014.01.013.

Jeong, C., Kang, H., Lee, M., Kim, D., Han, J., Hwang, D., Souissi, S., Lee, S., Shin, K., Park, H., Lee, J., 2017. Adverse effects of microplastics and oxidative stress-induced MAPK/Nrf2 pathway-mediated defense mechanisms in the marine copepod Paracyclopina nana. Sci. Rep. 7, 41323. https:// doi.org/10.1038/srep41323.

Jollès, J., Fiala-Médioni, A., Jollès, P., 1996. The ruminant digestion model using bacteria already employed early in evolution by symbiotic molluscs. J. Mol. Evol. 43, 523 527. PMID: 8875865.

Kaposi, K.L., Mos, B., Kelaher, B.P., Dworjanyn, S.A., 2014. Ingestion of microplastic has limited impact on a marine larva. Environ. Sci. Technol. 48, 16381645. https://doi.org/10.1021/es404295e.

Koelmans, A.A., Bakir, A., Burton, G.A., Janssen, C.R., 2016. Microplastic as a vector for chemicals in the aquatic environment: critical review and model-supported reinterpretation of empirical studies. Environ. Sci. Technol. 50, 33153326. https://doi.org/10.1021/acs.est.5b06069.

Lamb, J.B., Willis, B.L., Fiorenza, E.A., Couch, C.S., Howard, R., Rader, D.N., True, J.D. Kelly, L.A., Ahmad, A., Jompa, J., Harvell, C.D., 2018. Plastic waste associated with disease on coral reefs. Science 359, 460462. https:// doi.org/10.1126/science.aar3320.

Lee, K., Shim, W.J., Kwon, O.Y., Kang, J., 2013. Size-dependent effects of micro polystyrene particles in the marine copepod Tigriopus japonicus. Environ. Sci.

Technol. 47, 11278 11283. https://doi.org/10.1021/es401932b.

Lizárraga, D., Danihel, A., Pernet, B., 2017. Low concentrations of large inedible particles reduce feeding rates of echinoderm larvae. Mar. Biol. 164, 112. https://doi.org/10.1007/s00227-017-3134-9.

Long, M., Paul-Pont, I., Hégaret, H., Moriceau, B., Lambert, C., Huvet, A., Soudant, P., 2017. Interactions between polystyrene microplastics and marine phytoplankton lead to species-specific hetero-aggregation. Environ. Pollut. 228, 454 463. https://doi.org/10.1016/j.envpol.2017.05.047.

Lusher, A., 2015. Microplastics in the marine environment: distribution, interactions and effects. In: Bergmann, M., et al. (Eds.), Marine Anthropogenic Litter. Chapt.

10, pp. 245 307. https://doi.org/10.1007/978-3-319-16510-3_10.

Mazurais, D., Ernande, B., Quazuguel, P., Severe, A., Huelvan, C., Madec, L., Mouchel, O., Soudant, P., Robbens, J., Huvet, A., Zambonino-infante, J., 2015. Evaluation of the impact of polyethylene microbeads ingestion in European sea bass (Dicentrarchus labrax) larvae. Mar. Environ. Res. 112, $78 \quad 85$. https://doi.org/10.1016/j.marenvres.2015.09.009.

Mohammed, A., 2013. Why Are Early Life Stages of Aquatic Organisms More Sensitive to Toxicants than Adults? New Insights into Toxicity and Drug Testing. Gowder. https://doi.org/10.5772/55187. Chapt. 3. ISBN 978-953-51-0946-4.

Norén, F., 2007. Small Plastic Particles in Coastal Swedish Waters. N-research Report, Commissioned by KIMO Sweden, p. 11.

Passarelli, M.C., Riba, I., Cesar, A., Del Valls, T.A., 2018. What is the best endpoint for assessing environmental risk associated with acidification caused by $\mathrm{CO}_{2}$ enrichment using mussels? Mar. Pollut. Bull. 128, 379 389. https://doi.org/ 10.1016/j.marpolbul.2018.01.055.

Paul-Pont, I., Lacroix, C., González Fernández, C., Hégaret, H., Lambert, C., Le Goïc, N., Frere, L., Cassone, A.L., Sussarellu, R., Fabioux, C., Guyomarch, J., Albentosa, M., Huvet, A., Soudant, P., 2016. Exposure of marine mussels Mytilus spp. to polystyrene microplastics: toxicity and influence on fluoranthene bioaccumulation. Environ. Pollut. 216, 724 737. https://doi.org/10.1016/j.envpol.2016.06.039.

Pfaffl, M.W., Horgan, G.W., Dempfle, L., 2002. Relative expression software tool (REST) for group-wise comparison and statistical analysis of relative expression results in real-time PCR. Nucleic Acids Res. 30, e36. PMC113859.

Rahman, M.A., Yusoff, F., Arshad, A., Shamsudin, M.N., Amin, S.M.N., 2012. Embryonic, larval, and early juvenile development of the tropical sea urchin, Salmacis sphaeroides (echinodermata : echinoidea). Sci. World J. 2012, 938482 https:// doi.org/10.1100/2012/938482, 9 pp.

Revel, M., Châtel, A., Mouneyrac, C., 2018. Micro(nano)plastics: a threat to human health? Curr. Opin. Environ. Sci. Health 1, 17 23. https://doi.org/10.1016/ j.coesh.2017.10.003. 
Schmittgen, T.D., Livak, K.J., 2008. Analyzing real-time PCR data by the comparative CT method. Nat. Protoc. 3, 1101 1108. https://doi.org/10.1038/nprot.2008.73.

Schonitzer, V., Weiss, I.M., 2007. The structure of mollusc larval shells formed in the presence of the chitin synthase inhibitor Nikkomycin Z. BMC Struct. Biol. 7,

71. https://doi.org/10.1186/1472-6807-7-71.

Southgate, P.C., Braley, R.D., Militz, T.A., 2017. Ingestion and digestion of micro-

algaeoncentrates by veliger larvae of the giant clam, Tridacna noae. Aquaculture 473, 443 448. https://doi.org/10.1016/j.aquaculture.2017.02.032.

Sprung, M., 1984. Physiological energetics of mussel larvae (Mytilus edulis). Food uptake. Mar. Ecol. Prog. Ser. 17, 295 305. https://doi.org/10.3354/meps017295.

Sussarellu, R., Suquet, M., Thomas, Y., Lambert, C., Fabioux, C., Eve, M., Pernet, J., 2016. Oyster reproduction is affected by exposure to polystyrene microplastics. Proc. Natl. Acad. Sci. U.S.A. 113, 24302435. https:// doi.org/10.1073/pnas.1519019113.

UNEP, 2016. Marine plastic Debris and Microplastics Global Lessons and Research to Inspire Action and Guide Policy Change. United Nations Environment Programme, Nairobi. ISBN No: 978 92-807-3580-6.

UNESCO, 1981. Tenth Report of the Joint Panel on Oceanographic Tables and Standards. UNESCO Technical Papers in Marine Science. Paris, 25 p.

Viarengo, A. Lowe, D., Bolognesi, C., Fabbri, E., Koehler, A., 2007. The use of biomarkers in biomonitoring: a 2-tier approach assessing the level of pollutantinduced stress syndrome in sentinel organisms. Comp. Biochem. Physiol. C Toxicol. Pharmacol. 146, 281 300. https://doi.org/10.1016/j.cbpc.2007.04.011. von Moos, N., Burkhardt-holm, P., Kohler, A., 2012. Uptake and effects of microplastics on cells and tissue of the blue mussel Mytilus edulis L. after an experimental exposure. Environ. Sci. Technol. 46, 11327 11335. https:// doi.org/ 10.1021/es302332w.

Wang, Q., Zhang, L., Zhao, J., You, L., Wu, H., 2012. Two goose-type lysozymes in Mytilus galloprovincialis: possible function diversification and adaptive evolution. PLoS One 7, e45148. https://doi.org/10.1371/journal.pone.0045148.

Ward, J.E., Shumway, S.E., 2004. Separating the grain from the chaff: particle selection in suspension- and deposit-feeding bivalves. J. Exp. Mar. Biol. Ecol. 300, 83 130. https://doi.org/10.1016/j.jembe.2004.03.002.

Weiss, I.M., Schonitzer, V., 2006. The distribution of chitin in larval shells of the bivalve mollusk Mytilus galloprovincialis. J. Struct. Biol. 153, 264 277. https:// doi.org/10.1016/j.jsb.2005.11.006.

Widdows, J., 1991. Physiological ecology of mussel larvae. Aquaculture 94, 147163. https://doi.org/10.1016/0044-8486(91)90115-N.

Yin, H., Ji, B., Dobson, P.S., Mosbahi, K., Glidle, A., Gadegaard, N., Freer, A. Cooper, J.M., Cusack, M., 2009. Screening of biomineralization using micro-fluidics. Anal. Chem. 81, 473 478. https://doi.org/10.1021/ac801980b. Ziajahromi, S., Kumar, A. Neale, P.A., Leusch, F.D., 2017. Impact of microplastic beads and fibers on waterflea (Ceriodaphnia dubia) survival, growth, and reproduction: implications of single and mixture exposures. Environ. Sci. Technol. 51, 13397 13406. https://doi.org/10.1021/acs.est.7b03574. 